\title{
France takes control of genome programme
}

Paris. The French government is planning to take over direct control of publicly funded research on the human genome from its national genome agency, as part of a wider effort to develop a national strategy for the life sciences

Under plans due to be announced next week, funding for the agency, known as the Groupement de Recherches et d'Etudes sur les Génomes (GREG), will this year be reduced from FF80 million (US\$5.4 million) to FF20 million. Rather than supporting all genome research, the GREG will in future be restricted to funding work on model animals and plants.

The money taken from the GREG's budget will be given to the ministry of higher education and research to create new programmes on genetic function, medical genetics, and genetics and the environment.

\section{Technician charged after CERN sabotage}

Paris. A technician at the European Laboratory for Particle Physics (CERN), which straddles the border between France and Switzerland close to Geneva, has been charged with theft and extortion after the discovery that two accelerators at the centre had been sabotaged.

Early in the morning of 13 February, Nicolas Blazianu - who has worked at CERN for 27 years - cut cables and removed 1,200 electrical components needed for the running of the proton/synchroton (PS) accelerator and the PS booster (PSB). Both devices are used to accelerate electrons and positrons before these are introduced into CERN's large electron-positron collider (LEP).

The technician later called a member of CERN's management to demand a ransom of SFr2 million (US\$1.5 million) and the dismissal of his ex-wife, an administrator at the laboratory. But he eventually gave himself up, and has since provided CERN with information on the location of the components, which he had meticulously hidden around the CERN site.

It is not yet clear whether it will be possible for the accelerators, which had been shut down for maintenance in December, to be restarted in April as had been planned. Even if the components have not been damaged, the accelerators will need to be recalibrated and their beams retuned before being put back in operation.

Following the charges against Blazianu, CERN has itself launched an internal inquiry into the incident and its consequences for the running schedule of the site. The ease with which the centre's machines were sabotaged is likely to result in a review of internal security procedures.

D.B.
Each will be run by an expert committee set up within the science ministry.

Claude Griscelli - an adviser to Francois Fillon, the science minister, and considered to be the main architect of the planned national strategy for life sciences - claims that the ministry is well placed to "coordinate" the genome research carried out by the various research organizations.

Indeed, this is the philosophy behind the national strategy for life sciences itself, which will group all biological research carried out by the Centre National de la Recherche Scientifique (CNRS), the Institut Nationale pour la Santé et Recherche Medicale (INSERM), and other research organizations within 14 "horizontal" themes, each run by an expert committee. Details of the themes have yet to be announced.

But the planned changes in the organization of genome research are being strongly opposed by Piotr Slonimski, the director of GREG. He argues that it will not provide any extra money for such research, but will merely introduce new layers of bureaucracy which could, be claims, delay procedures for approving and financing grants; at present, he says, the GREG pays out grants within two weeks of approving a research proposal.

Slonimski also points out that, even though GREG will receive FF20 million this year, the agency has only FF8 million left to launch new programmes, claiming that the ministry wants to abolish GREG.

GREG's scientific board decided last week to evaluate all the research proposals it has in hand. Those that fall within its new restricted jurisdiction will be financed; its evaluations of the rest will be forwarded to the ministry "to take into account or not, as it sees fit".

Some claim that the change has been prompted by a feeling in both scientific and political circles that the policies of the

GREG have not been sufficiently ambitious. But they are reluctant to criticize Slonimski, arguing that he should be given credit both as an eminent geneticist, and for having brought order to France's fragmented genome efforts.

Slonimski accepts that his support for academic laboratories has been eclipsed by the success of the industrial-scale approach to genome sequencing and related research pursued by the Généthon laboratory outside Paris. But he argues that the two strategies have not been incompatible.

Indeed, Slonimski points out that although GREG has spent most of its funds on research carried out by Généthon, he has felt it important to fund laboratories working in other areas as well. The new plan, he complains, will separate responsibility for research on the human genome from studies of the genomes of other model organisms.

One CNRS official acknowledges that the ministry has been motivated by a desire to take control of human genome research out of GREG's hands. But, he argues, fears that this would lead to genome research becoming "more medical and applied" have not been borne out. "CNRS labs will be able to get funding [for genome research] without compromising their mission [to do basic research]," he says.

The official also defends the ministry's decision to take over responsibility for bioinformatics from GREG, arguing that this is a generic tool that needs to be coordinated across all biological research.

Few details of the ministry's planned national strategy for the life sciences are yet available. But some feel that these are likely to be less ambitious than initially expected; plans for interministerial collaboration for example, have fallen through because of disagreement over territorial responsibility.

Declan Butler

\section{Indian confirms identity of plague}

New Delhi. An independent committee set up by the Indian government has confirmed that the disease that broke out in Surat four months ago was indeed plague- refuting earlier reports that some other cause might have been responsible (see Nature, 371, 547; 1994).

The committee's interim report endorses the earlier findings of a team from the World Health Organisation (WHO) and finally puts to rest the controversy triggered by various Indian microbiologists - including N. P. Gupta, a former director of the National Institute of Virology - and based on what were described at the time by some scientists as various "baffling and mysterious" aspects of the outbreak.

The committee was made up of 11 lead- ing microbiologists and epidemiologists, and was formed immediately after the departure of the WHO team. It claims to have isolated and grown the causative agent and identified it as Yersinia pestis after a battery of biochemical tests (the WHO team relied on circumstantial and sero-epidemiological data). Final confirmation came from PCR analysis of DNA extracted from the isolates and autopsy specimens.

Meanwhile the government is considering a \$30-million proposal to establish a national disease surveillance network which would provide warning of any local outbreak of a disease before it becomes an epidemic. The network would be run by the National Institute of Communicable Diseases in New Delhi.

K. S. Jayaraman 